•生物编目・

\title{
龙栖山自然保护区蝴蝶群落多样性及区系组成
}

\author{
洪 芳 ${ }^{1}$ 向 颖 $^{2} \quad$ 陈朝阳 ${ }^{1} \quad$ 孙亮先 $^{1}$ 罗春首 $^{3}$ 蒋国芳 $^{1^{*}}$ \\ 1 (泉州师范学院海洋与食品学院, 福建泉州 362000 ) \\ 2 (吉首大学生物资源与环境科学学院, 湖南吉首 416000) \\ 3 (福建龙栖山国家级自然保护区管理局, 福建三明 353305)
}

\begin{abstract}
摘要: 蝴蝶是生态质量和环境变化的重要指示生物。查明福建省龙栖山国家级自然保护区蝴蝶资源及其动态对龙 栖山生物多样性保护和研究具有重要意义。通过2016-2018年对龙栖山自然保护区蝴蝶的持续调查和观测, 应用 Shannon-Wiener指数及相对多度分析研究了蝴蝶的多样性、种群动态和区系成分。结果表明: 龙栖山自然保护区 的蝶类有5科107属193种。在龙栖山样区设置的6条样线中, 小沛样线的属和种数均为最多, 共 48 属58种; 属于国家 保护的蝴蝶有6种; 区系组成主要以东洋种成分 (79.3\%)为主, 广布种成分次之(21.2\%); 蝴蝶优势种组成在不同年 度间稍有变化, 持续稳定的优势种为䇾眼蝶(Ypthima baldus)。
\end{abstract}

关键词: 群落多样性; 种群动态; 优势种; 区系分析; 龙栖山自然保护区; 蝴蝶观测

\section{Community diversity and faunal composition of butterflies in the Longqishan Nature Reserve}

\author{
Fang Hong ${ }^{1}$, Ying Xiang ${ }^{2}$, Chaoyang Chen ${ }^{1}$, Liangxian Sun ${ }^{1}$, Chunshou Luo ${ }^{3}$, Guofang Jiang ${ }^{1 *}$ \\ 1 College of Oceanology and Food Science, Quanzhou Normal University, Quanzhou,Fujian 362000 \\ 2 Institute of Biological Resources and Environmental Science, Jishou University, Jishou, Hunan 416000 \\ 3 Longqishan National Nature Reserve Administration, Sanming, Fujian 353305
}

\begin{abstract}
Butterfly is an important indicator of ecological quality and environmental change. Finding out the butterfly resources and their dynamics in Longqishan National Nature Reserve in Fujian Province is of great significance to the conservation and research of Longqishan biodiversity. We analyzed the butterfly diversity, population dynamics, and faunal composition throughout the nature reserve using Shannon-wiener index and relative abundance and continuous observations over a three year period (2016-2018). We recorded five families, 107 genera, and 193 species of butterflies in the Longqishan Nature Reserve. Among the six sample lines in the Longqi Mountains area surveyed, the greatest number of genera and species was recorded on the Xiaopei sample line, with 48 genera and 58 species recorded in total. Six recorded butterfly species are under state protection. Overall, the faunal composition was dominated by Oriental species (79.3\%) followed by widespread species (21.2\%). The dominant butterfly species composition did not vary significantly between years. The continuously stable, dominant species recorded was Ypthima baldus.
\end{abstract}

Key words: community diversity; population dynamics; dominant species; fauna analysis; Longqishan Nature Reserve; butterfly observation

蝴蝶是生态环境的指示性昆虫, 大部分蝶类对 环境变化敏感, 可以很好地反映环境的质量和变化, 还可以作为生物多样性丰富程度的指示物种, 间接 地反映生物多样性的变化(Pollard \& Yates, 1993; Hermy \& Cornelis, 2000; 王敏等, 2003)。不同地理种
群是生态环境的产物, 蝴蝶的生态地理分布主要受 食物、植被、土壤结构、温湿度等生态因子的影响。 龙栖山国家级自然保护区(以下简称“龙栖山保 护区”)位于浙闽山地, 在全球 25 个重要的生物多样 性热点之一的中国中南部(South-Central China)的东 
部(Myers et al, 2000), 是我国陆地生物多样性关键 地区，也是目前华东地区森林保存较好、面积最大 的区域(陈灵芝, 1993)。该地区的生物资源虽然丰富, 但过度的开发已造成普遍的资源枯竭, 加强保护和 实现可持续利用是迫切之需(陈灵芝, 1993)。中国 科 学院动物研究所于1990-1991年在龙栖山保护区内 开展了全面调查研究, 出版专著《龙栖山动物》(黄 春梅等, 1993)。该书记载的昆虫种类约占福建省昆 虫种类数的 $1 / 3$, 而龙栖山面积仅占全省面积的 $1 / 2,000$, 并首次记载了龙栖山蝴蝶 10 科 72 属 104 种, 但无绢蝶科和珍蝶科记录。此后未见有龙栖山蝴蝶 的研究报道。

根据生态环境部蝴蝶多样性观测网络的统一 要求(马方舟等, 2018), 2016-2018年我们对龙栖山 自然保护区的蝴蝶进行了连续3年的观测调查, 结 合前人的相关资料，分析龙栖山自然保护区的蝶类 蝴蝶多样性和福建省鳞翅目昆虫区系的全貌提供 参考。

\section{研究区域概况}

龙栖山国家级自然保护区位于福建省将乐县 境内 $\left(117^{\circ} 13^{\prime}-117^{\circ} 21^{\prime} \mathrm{E} 、 26^{\circ} 28^{\prime}-26^{\circ} 37^{\prime} \mathrm{N}\right)$, 属武夷 山脉东南延伸的支脉; 海拔235-1,620 m, 南北长18 $\mathrm{km}$, 东西宽 $14 \mathrm{~km}$, 保护区总面积 $156.93 \mathrm{~km}^{2}$ 。东南 接白莲镇, 北靠黄潭镇, 西连万全乡, 西南与明溪 县交界。地处中国南北亚热带交替区域, 千米以上 高峰有 40 余座, 最高峰海拔 $1,620 \mathrm{~m}$ 。年均气温 $16^{\circ} \mathrm{C}$, 1 月平均气温 $6.2^{\circ} \mathrm{C}, 7$ 月平均气温为 $25.3^{\circ} \mathrm{C}$, 比区外 低 $5.8^{\circ} \mathrm{C}$, 绝对最低气温 $-8.3^{\circ} \mathrm{C}$, 绝对最高气温 $32^{\circ} \mathrm{C}$ 。年平均降水量 $1,797 \mathrm{~mm}$, 雨季主要在春夏, 秋冬降水量较少。该保护区自然生态环境良好, 保 存着丰富、完整的原始森林, 森林覆盖率达96.5\%; 珍稀动物较多, 如国家一级保护动物有金钱豹 (Panthera pardus)、云豹(Neofelis nebulosa)、黄腹角 雉(Tragopan caboti)、白颈长尾雉(Sytmaticus ellioti)、 黑鹿(Muntiacus crinifrons)、蟒(Python molurus)等, 生 物多样性资源丰富(黄春梅等, 1993)。

\section{2 方法}

\section{1 样线设置}

为了充分体现龙栖山样区的生物多样性, 依据

全国统一的样线调查法(马方舟等, 2018), 我们在保 护区的实验区和缓冲区分别设置了 3 条样线, 每条 样线代表不同的海拔、植被和生境类型如森林、草 地、菜地、田埂等。在2016-2018年的每年6个月里 (4-9月), 对龙栖山自然保护区6条样线(龙潭、田角、 沙溪仔、小沛、小王水库段和沙洲村)进行调查。在 无雨、无较强干扰因素条件下，尽量做到各月份同 一日期(20日)调查。

\section{2 调查与观测方法}

每条样线长度 $2 \mathrm{~km}$, 划分成 10 个样段, 平均每 样段 $200 \mathrm{~m}$, 每个样段内生境类型或土地利用方式 相同。各样线、样段设置明显标识物并编号标记。 选定样线后，用基于安卓系统的手机应用“GPS工 具箱”定位坐标, 在1:10,000地图上标注样线的路 线。

观测时沿样线缓慢匀速前行, 速度1-1.5 km/h, 时间控制在 $80 \mathrm{~min}$ 左右。记录样线左右各 $2.5 \mathrm{~m}$ 、上 方 $5 \mathrm{~m}$ 、前方 $5 \mathrm{~m}$ 范围内见到的所有蝴蝶的种类和数 量(马方舟等, 2018)。记录迎面飞来的蝴蝶, 不重复 计数同一只个体及身后的蝴蝶。在悬崖或水边, 沿 样线记录一侧宽度为 $5 \mathrm{~m}$ 范围内的数据, 在观测范 围之外见到的蝴蝶种类, 写入备注栏中。若蝴蝶数 量过多, 登记估计值或使用相机拍摄后计数。

对于不能确定的种类，网捕或者拍照后进行鉴 定。对网捕的蝴蝶种类确定后原地释放; 当场不能 确定的种类, 用捕虫网采集, 放入三角纸袋中, 并 记录采集地点、时间、采集人，带回实验室鉴定、 统计记录或拍照后依据照片和标本特征数据比对 相关书籍检索鉴定。

\section{3 分类和区系划分依据}

对野外获得的标本, 依据《中国蝶类志》(周尧, 1994)、《中国蝴蝶图鉴》(武春生和徐䏴峰, 2017)、 《台湾蝴蝶图鉴》(徐垤峰, 2013) 等资料进行检索鉴 定和归类。根据各物种在我国的地理分布记录进行 区系成分划分(王敏等, 2003), 把跨越两个或两个以 上大动物地理区的种类称为广布种; 主要或完全分 布于东洋区的种类称为东洋种; 古北界中的物种称 为古北种(洪芳等, 2004)。

\section{4 数据整理和分析方法}

对上述获得的数据进行整理和统计, 并对统计 的数据进行相对多度和Shannon-Wiener指数分析。 
Shannon-Wiener指数(Shannon \& Weaver, 1949; 王敏等, 2003): $H^{\prime}=-\sum P i \ln P i$ 。 $P i$ 为种 $i$ 的个体数占 总个体数的比例。

在每条样线的每次观测中能被发现或采集到 10 个及以上个体的蝴蝶种, 我们拟定为优势种。

观测和整理的最终结果提交至全国蝴蝶多样 性观测平台(China BON-Butterflies, http://58.213. 151.82:9966/)。

\section{3 结果}

\section{1 龙栖山自然保护区蝴蝶种类组成}

3年中, 在龙栖山自然保护区共观测到蝴蝶 5,171只，分属于5科107属193种(附录1)。其中凤蝶 科4属18种, 粉蝶科7属10种, 蛱蝶科53属106种, 灰 蝶科24属30种，弄蝶科19属29种，总体上增加了 134种在《龙栖山动物》(黄春梅, 1993)一书中未曾 记载的蝴蝶。根据2000年国家林业局颁布的《国家 保护的有益的, 或者有重要经济、科学研究价值的 野生动物名录》，龙栖山保护区内属于国家保护的 蝴蝶种类有6种，即金裳风蝶(Troides aeacus)、宽尾 凤蝶 (Papilio elwesi)、箭环蝶 (Stichophthalma howqua)、华西箭环蝶(S. suffuse)、枯叶蛱蝶(Kallima inachus) 和 虎 斑 灰 蝶 (Yamamotozephyrus kwangtungensis), 占我国两次颁布(1989和2000年) 的保护物种名录中蝶类总数量(83种)的 $7.2 \%$ 。

\section{2 区系地理成分}

龙栖山自然保护区的蝶类中, 广布种已知 32 属 41 种 (附录 1 ), 分别占保护区蝴蝶属、种总数的 $29.9 \%$ 和 $21.2 \%$; 东洋种有 86 属 151 种(附录1), 分别
占 $80.4 \%$ 和 $78.2 \%$ 。出现了 1 个古北种(附录1), 即小 弄蝶(Leptalina unicolor)。

\section{3 龙栖山自然保护区蝶类的多样性}

\subsection{1 各样线蝴蝶物种多样性}

从统计结果(表1)来看, 在龙栖山样区设置的6 条样线中, 小沛样线的属数和种数均为最多, 共 48 属58种; 小王水库段最少，共25属34种，这应与小 王水库段人为活动频繁、植被较单一有关。

\subsection{2 优势种组成}

2016 年, 龙栖山蝴蝶优势种主要有宽边黄粉蝶 (Eurema hecabe)、蒙链荫眼蝶(Neope muirheadii)、 连纹黛眼蝶 (Lethe syrcis)、翟眼蝶(Ypthima baldus) 和斐豹蛱蝶(Argyreus hyperbius); 2017年，有宽边黄 粉蝶、东方菜粉蝶(Pieris canidia)、荁麻珍蝶(Acraea issoria)、䇱眼蝶和酢酱灰蝶(Zizeeria maha); 2018 年, 有东方菜粉蝶、长尾榛风蝶(Byasa impediens)、连纹

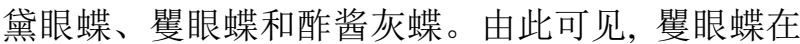
3 个年度均是优势种, 是该保护区活动表现最为稳 定的蝴蝶优势种。

\subsection{3 物种多样性指数}

从Shannon-Wiener多样性指数计算结果来看, 龙栖山自然保护区具有较高的蝶类多样性(表2), 这 与保护区多年来注重自然保护，避免人为破坏有一 定的关系。从多样性指数年度变化来看, 龙栖山保 护区2017年的物种多样性指数最高(5.0442), 而 2018年的物种多样性指数降低的主要原因是当年6 月份整个福建省受到了台风暴雨天气的较大影响。

\section{4 种群动态}

在2016-2018年，蝴蝶种数以 2017 年最多(129

表1 龙栖山保护区6个样线的蝴蝶属种数量

Table 1 The number of species and genus of butterflies in six lines in the Longqishan Nature Reserve

\begin{tabular}{|c|c|c|c|c|c|c|c|c|c|c|c|c|}
\hline \multirow[t]{2}{*}{$\begin{array}{l}\text { 科 } \\
\text { Family }\end{array}$} & \multicolumn{2}{|l|}{$\begin{array}{l}\text { 龙潭 } \\
\text { Longtan } \\
\end{array}$} & \multicolumn{2}{|c|}{$\begin{array}{l}\text { 沙溪仔 } \\
\text { Shaxizhai } \\
\end{array}$} & \multicolumn{2}{|c|}{$\begin{array}{l}\text { 小王水库 } \\
\text { Xiaowang reservoir }\end{array}$} & \multicolumn{2}{|c|}{$\begin{array}{l}\text { 沙洲村 } \\
\text { Shazhoucun }\end{array}$} & \multicolumn{2}{|l|}{$\begin{array}{l}\text { 田角 } \\
\text { Tianjiao } \\
\end{array}$} & \multicolumn{2}{|l|}{$\begin{array}{l}\text { 小沛 } \\
\text { Xiaopei }\end{array}$} \\
\hline & $\begin{array}{l}\text { 属 } \\
\text { Genera }\end{array}$ & $\begin{array}{l}\text { 种 } \\
\text { Species }\end{array}$ & $\begin{array}{l}\text { 属 } \\
\text { Genera }\end{array}$ & $\begin{array}{l}\text { 种 } \\
\text { Species }\end{array}$ & $\begin{array}{l}\text { 属 } \\
\text { Genera }\end{array}$ & $\begin{array}{l}\text { 种 } \\
\text { Species }\end{array}$ & $\begin{array}{l}\text { 属 } \\
\text { Genera }\end{array}$ & $\begin{array}{l}\text { 种 } \\
\text { Species }\end{array}$ & $\begin{array}{l}\text { 属 } \\
\text { Genera }\end{array}$ & $\begin{array}{l}\text { 种 } \\
\text { Species } \\
\end{array}$ & $\begin{array}{l}\text { 属 } \\
\text { Genera }\end{array}$ & $\begin{array}{l}\text { 种 } \\
\text { Species }\end{array}$ \\
\hline $\begin{array}{l}\text { 凤蝶科 } \\
\text { Papilionidae }\end{array}$ & 2 & 5 & 3 & 4 & 1 & 3 & 3 & 9 & 2 & 3 & 3 & 4 \\
\hline $\begin{array}{l}\text { 粉蝶科 } \\
\text { Pieridae }\end{array}$ & 2 & 3 & 2 & 4 & 2 & 2 & 2 & 2 & 2 & 2 & 3 & 3 \\
\hline $\begin{array}{l}\text { 蛱蝶科 } \\
\text { Nymphalidae }\end{array}$ & 18 & 27 & 17 & 29 & 11 & 16 & 21 & 23 & 21 & 27 & 29 & 38 \\
\hline $\begin{array}{l}\text { 灰蝶科 } \\
\text { Lycaenidae }\end{array}$ & 9 & 10 & 7 & 8 & 8 & 10 & 6 & 7 & 7 & 7 & 9 & 9 \\
\hline $\begin{array}{l}\text { 弄蝶科 } \\
\text { Hesperiidae }\end{array}$ & 6 & 7 & 2 & 2 & 3 & 3 & 2 & 2 & 4 & 6 & 4 & 4 \\
\hline $\begin{array}{l}\text { 合计 } \\
\text { Total }\end{array}$ & 37 & 52 & 31 & 47 & 25 & 34 & 34 & 43 & 36 & 45 & 48 & 58 \\
\hline
\end{tabular}


表2 龙栖山自然保护区蝶类群落多样性指数

Table 2 Species diversity index of butterflies in the Longqishan Nature Reserve

\begin{tabular}{lllll}
\hline $\begin{array}{l}\text { 年度 } \\
\text { Year }\end{array}$ & $\begin{array}{l}\text { 科数 } \\
\text { Family }\end{array}$ & $\begin{array}{l}\text { 种数 } \\
\text { Species }\end{array}$ & $\begin{array}{l}\text { 个体数 } \\
\text { Individual }\end{array}$ & $\begin{array}{l}\text { Shannon-Wiener } \\
\text { 指数 } \\
\text { Shannon-Wiener } \\
\text { index }\end{array}$ \\
\hline 2016 & 5 & 88 & 1,184 & 4.9590 \\
2017 & 5 & 129 & 1,936 & 5.0442 \\
2018 & 5 & 110 & 2,037 & 5.0325 \\
\hline
\end{tabular}

种), 个体数则是逐年递增, 以2018年为最多 $(2,037)$ (表2)。

龙栖山各月份蝴蝶种群数量动态分析表明: 每 年的蝴蝶种类数以 6 月份最多, 而个体数则主要以 9 月份最多(表3)。

\section{4 讨论}

龙栖山自然保护区的蝶类资源非常丰富。仅从 跟踪观测的6条样线的调查结果来看, 就有 5 科 107 属193种。从属种的区系组成和数量分配上来看, 龙 栖山自然保护区蝶类以东洋种成分占绝对优势地 位，有86属153种，占该保护区属、种总数的 $80.4 \%$

表3 龙栖山每年6个月份蝴蝶的种数和个体数
和78.2\%, 这与其温暖湿润的气候和复杂的地形地 貌密切相关。另外还发现了1个古北种, 即小弄蝶。

对于福建省蝴蝶的种类, 徐奇涵(2004)统计有 11科224属545种, 比《福建昆虫志(第四卷)》(黄邦 㑆，2001)中记录的多了30种，但缺乏正式发表的详 细名录, 因此本文并不以此为据。本文认可《福建 昆虫志(第四卷)》的可靠性。从与福建全省蝴蝶种 类和数量的比较来看, 据中国蝴蝶分类系统(周尧, 1994), 福建蝶类有11科(黄邦㑆，2001), 而根据现 行国际蝴蝶分类系统，即凤蝶科、粉蝶科、蛱蝶科、 灰蝶科和弄蝶科 5 科系统, 这5科的种类在福建省均 有; 龙栖山自然保护区也有这5科蝴蝶。根据《龙栖 山动物》记录的蝴蝶, 缺少珍蝶科, 即现行国际分 类系统中的蛱蝶亚科的珍蝶族(Acraeini), 也缺少绢 蝶科, 即现行的绢蛱蝶亚科(Calinaginae)。可是在我 们这3年的蝴蝶观测中发现隶属于珍蝶族的苦麻珍 蝶是龙栖山蝴蝶的 1 个常见种。我们推测, 当年中国 科学院动物所在进行龙栖山昆虫考察时并未采集 到拦麻珍蝶。龙栖山蛱蝶科的资源非常丰富, 共有 53 属，占福建全省蛱蝶种类的 $65.4 \%$ 。

Table 3 Species and individual numbers of butterflies in Longqishan in six months every year

\begin{tabular}{|c|c|c|c|c|c|c|c|c|c|c|c|c|c|c|}
\hline \multirow{2}{*}{$\begin{array}{l}\text { 年度 } \\
\text { Year }\end{array}$} & \multicolumn{2}{|c|}{ 4月 April } & \multicolumn{2}{|c|}{ 5月 May } & \multicolumn{2}{|c|}{ 6月 June } & \multicolumn{2}{|c|}{ 7月 July } & \multicolumn{2}{|c|}{ 8月 August } & \multicolumn{2}{|c|}{ 9月 September } & \multicolumn{2}{|c|}{ 10月 October } \\
\hline & $\begin{array}{l}\text { 种数 } \\
\text { Species }\end{array}$ & $\begin{array}{l}\text { 个体数 } \\
\text { Inds. }\end{array}$ & $\begin{array}{l}\text { 种数 } \\
\text { Species }\end{array}$ & $\begin{array}{l}\text { 个体数 } \\
\text { Inds. }\end{array}$ & $\begin{array}{l}\text { 种数 } \\
\text { Species }\end{array}$ & $\begin{array}{l}\text { 个体数 } \\
\text { Inds. }\end{array}$ & $\begin{array}{l}\text { 种数 } \\
\text { Species }\end{array}$ & $\begin{array}{l}\text { 个体数 } \\
\text { Inds. }\end{array}$ & $\begin{array}{l}\text { 种数 } \\
\text { Species }\end{array}$ & $\begin{array}{l}\text { 个体数 } \\
\text { Inds. }\end{array}$ & $\begin{array}{l}\text { 种数 } \\
\text { Species }\end{array}$ & $\begin{array}{l}\text { 个体数 } \\
\text { Inds. }\end{array}$ & $\begin{array}{l}\text { 种数 } \\
\text { Species }\end{array}$ & $\begin{array}{l}\text { 个体数 } \\
\text { Inds. }\end{array}$ \\
\hline 2016 & - & - & 33 & 155 & 52 & 170 & 38 & 217 & 35 & 260 & 42 & 454 & 7 & 11 \\
\hline 2017 & 27 & 107 & 41 & 264 & - & - & 48 & 222 & 53 & 434 & 54 & 738 & 54 & 293 \\
\hline 2018 & 42 & 212 & 49 & 563 & 53 & 232 & 33 & 176 & - & - & 52 & 402 & 42 & 309 \\
\hline
\end{tabular}

一数据缺失(因台风、暴雨等极端天气无法观测) - Lack of data (cannot be observed due to typhoons, torrential rains and other extreme weather)

从多样性来看, 将乐县龙栖山自然保护区具有 较高的蝶类多样性, 除了跟龙栖山独特的地理环境 因素有关, 还与当地注重保护生态环境资源密不可 分。但是在观测过程中, 我们发现该保护区尚存在 一些生境破坏等人为干扰的因素。龙栖山蝴蝶多样 性面临的威胁因素主要是植被破坏, 如砍伐和运输 竹子及清除下层小灌木丛(为方便砍竹及运竹), 这 些行为主要对竹林中蝴蝶生存影响较大。其次是旅 游开发, 建议今后注意适度控制旅游人数和路线。

\section{参考文献}

Chen LZ (1993) Biodiversity in China: The Present Situation of and Its Protection Measures. Science Press, Beijing. [陈灵芝 (1993) 中国的生物多样性：现状及其保护对策. 科学出 版社, 北京.]

Chou I (1994) Monographia Rhopalocerorum Sinensium. Henan Science and Technology Press, Zhengzhou. (in Chinese) [周尧 (1994) 中国蝶类志(上、下册). 河南科学 技术出版社, 郑州.]

Hermy M, Cornelis J (2000) Towards a monitoring method and a number of multifaceted and hierarchical biodiversity indicators for urban and suburban parks. Landscape and Urban Planning, 49, 149-162.

Hong F, Jiang GF, Zhou SY (2004) A composition analysis of the butterfly fauna of Shiwandashan Mountain in Guangxi. Journal of Nanjing Normal University (Natural Science Edition), 27(2), 87-90. (in Chinese with English abstract) 
[洪芳, 蒋国芳, 周善义 (2004) 广西十万大山蝶类区系 组成的初步研究. 南京师大学报(自然科学版), 27(2), 87-90.]

Huang BK (2001) Fauna of Insects in Fujian Province of China, Vol. 4. Fujian Science and Technology Press, Fuzhou. (in Chinese) [黄邦㑆 (2001) 福建昆虫志(第四 卷). 福建科学技术出版社, 福州.]

Huang CM (1993) Animals in Longqi Mountains. China Forestry Publishing House, Beijing. (in Chinese) [黄春梅 (1993) 龙栖山动物. 中国林业出版社, 北京.]

Ma FZ, Xu HG, Chen MM, Tong WJ, Wang CB, Cai L (2018) Progress in construction of China butterfly diversity observation network (China BON-Butterflies). Journal of Ecology and Rural Environment, 34(1) , 27-36. (in Chinese with English abstract) [马方舟, 徐海根, 陈萌萌, 童文君, 王晨涁, 蔡蕾 (2018) 全国蝴蝶多样性观测网络(China BON-Butterflies)建设进展. 生态与农村环境学报, 34, 27-36.]

Myers N, Mittermeier RA, Mittermeier CG, da Fonseca AB, Kent J (2000) Biodiversity hotspots for conservation priorities. Nature, 403, 853-858.

Pollard E, Yates TJ (1993) Monitoring Butterflies for Ecology and Conservation: The British Butterfly Monitoring Scheme. Chapman and Hall, London.
Shannon C, Weaver W (1949) The Mathematical Theory of Communication. Urbana University of Illinois Press, Illinois.

Wang M, Huang GH, Fan XL, Xie GZ, Huang LS, Dai KY (2003) Species diversity of butterflies in Shimentai Nature Reserve, Guangdong. Biodiversity Science, 11, 441-453. (in Chinese with English abstract) [王敏, 黄国华, 范骁凌, 谢 国忠, 黄林生, 戴克元 (2003) 石门台自然保护区蝴蝶物 种多样性研究. 生物多样性, 11, 441-453.]

Wu CS, Xu YF (2017) Butterflies of China. The Straits Publishing House, Fuzhou. (in Chinese) [武春生, 徐堉峰 (2017) 中国蝴蝶图鉴. 海峡书局, 福州.]

Xu QH (2004) A overview of butterfly resources in Fujian Province. Journal of Fujian Institute of Education, 16(10), 110-112. (in Chinese with English abstract) [徐奇涵 (2004) 福建省蝶类资源概述. 福建教育学院学报, 16(10), 110-112.]

Xu YF (2013) Butterflies of Taiwan (Parts I, II, III). Morning Star Publishing Ltd., Taizhong. (in Chinese) [徐堉峰 (2013) 台湾蝴蝶图鉴(上、中、下). 晨星出版有限公司, 台 中.]

(责任编委: 朱朝东 责任编辑: 时意专)

\section{附录 Supplementary Material}

附录1 龙栖山国家级自然保护区蝶类名录

Appendix 1 List of butterfly species recorded in Longqishan National Nature Reserve http://www.biodiversity-science.net/fileup/PDF/2020203-1.pdf

\section{附录2 蝴蝶在各样线的分布信息}

Appendix 2 Distribution information of butterflies in each sample line http://www.biodiversity-science.net/fileup/PDF/2020203-2.pdf 
洪芳, 向颖, 陈朝阳, 孙亮先, 罗春首, 蒋国芳 (2020) 龙栖山自然保护区蝴蝶群落多样性及区系. 生物多样性, 28 (8): 1003-1007. http://www.biodiversity-science.net/CN/10.17520/biods.2020203

附录 1 龙栖山国家级自然保护区蝶类名录。表格中标有\#者, 示在《龙栖山动物》中未曾记录的蝶种。

Appendix 1 Species list of butterflies recorded in the Longqishan National Nature Reserve

\begin{tabular}{lllll}
\hline 种名及分类归属 & 个体数 & 东洋种 & 古北种 & 广布种 \\
Species and classification & Individual & Oriental & Palaearctic & Widespread \\
& number & species & species & species \\
\hline
\end{tabular}

\section{1 凤蝶科 Papilionidae}

1) 金裳凤蝶 Troides aeacus (C.\& R.Felder) \#

2) 中华廂凤蝶 Byasa confusus (Jordan)

3) 长尾鹿蝶 Byasa impediens (Seita)

4) 灰绒謝风蝶 Byasa mencius (C.\& R.Felder)

5) 宽尾凤蝶 Papilio elwesi Leech \#

6) 玉带凤蝶 Papilio polytes Linnaeus

7) 玉斑凤蝶 Papilio helenus Linnaeus\#

8) 蓝凤蝶 Papilio protenor Cramer

9) 美凤蝶 Papilio memnon Linnaeus \#

10) 碧凤蝶 Papilio bianor Cramer

11) 柑橘凤蝶 Papilio xuthus Linnaeus

12）金凤蝶 Papilio machaon Linnaeus\#

13）宽带青凤蝶 Graphium cloanthus (Westwood) \#

14) 青凤蝶 Graphium sarpedon (Linnaeus) \#

15）碎斑青凤蝶 Graphium chironides (Honrath) \#

16) 木兰青凤蝶 Graphium doson (C.\& R.Felder) \#

17) 穹翠凤蝶 Papilio dialis (Leech) \#

18）巴黎翠凤蝶 Papilio paris Linnaeus \#

\section{2 粉蝶科 Pieridae}

1) 迁粉蝶 Catopsilia pomona (Fabricius) \#

2) 黑角方粉蝶 Dercas lycorias (Doubleday) \#

3) 尖角黄粉蝶 Eurema laeta (Boisduval) \#

4) 宽边黄粉蝶 Eurema hecabe (Linnaeus)

5) 檗黄粉蝶 Eurema blanda (Boisduval) \#

6) 酒青斑粉蝶 Delias sanaca (Moore) \#

7) 锯粉蝶 Prioneris thestylis (Doubleday) \#

8) 菜粉蝶 Pieris rapae (Linnaeus)

9) 东方菜粉蝶 Pieris canidia (Sparrman)

10) 飞龙粉蝶 Talbotia naganum (Moore) \#

\section{3 蛱蝶科 Nymphalidae}

1) 暮眼蝶 Melanitis leda (Linnaeus)

2) 睇暮眼蝶 Melanitis phedima (Cramer) \#

3) 黛眼蝶 Lethe dura (Marshall) \#

4) 连纹黛眼蝶 Lethe syrcis Hewitson

5) 宽带黛眼蝶 Lethe helena Leech \#

6) 棕褐黛眼蝶 Lethe christophi Leech

7) 深山黛眼蝶 Lethe hyrania (Kollar) \#

2
3
2
3
1
1
67
2
8
14
4
1
7
41
3
1
3
10

2
34
240
3
1
16
67
21
8
14
4
1
7
41
3
3

16

67

21

41

\section{3}
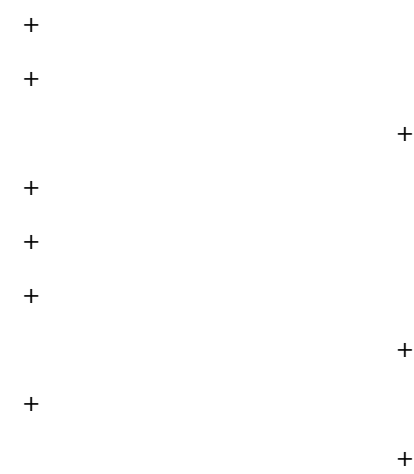

$+$
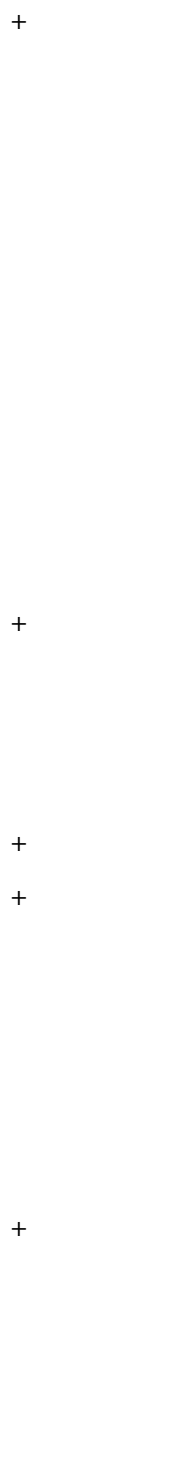
洪芳, 向颖, 陈朝阳, 孙亮先, 罗春首, 蒋国芳 (2020) 龙栖山自然保护区蝴蝶群落多样性及区系. 生物多样性, 28 (8): 1003-1007. http://www.biodiversity-science.net/CN/10.17520/biods.2020203

\begin{tabular}{|c|c|c|c|c|}
\hline $\begin{array}{l}\text { 种名及分类归属 } \\
\text { Species and classification }\end{array}$ & $\begin{array}{l}\text { 个体数 } \\
\text { Individual } \\
\text { number }\end{array}$ & $\begin{array}{l}\text { 东洋种 } \\
\text { Oriental } \\
\text { species }\end{array}$ & $\begin{array}{l}\text { 古北种 } \\
\text { Palaearctic } \\
\text { species }\end{array}$ & $\begin{array}{l}\text { 广布种 } \\
\text { Widespread } \\
\text { species }\end{array}$ \\
\hline 9) 玉带黛眼蝶 Lethe verma (Kollar) \# & 4 & + & & \\
\hline 10) 尖尾黛眼蝶 Lethe sinorix (Hewitson) \# & 1 & + & & \\
\hline 11）蛇神黛眼蝶 Lethe satyrina Bulter & 2 & + & & \\
\hline 12）曲纹黛眼蝶 Lethe chandica Moore & 121 & + & & \\
\hline 13) 三楔黛眼蝶 Lethe mekara Moore \# & 5 & + & & \\
\hline 14）阿芒荫眼蝶 Neope armandii (Oberthür) \# & 3 & + & & \\
\hline 15) 布莱荫眼蝶 Neope bremeri (C.\& R.Felder) \# & 6 & + & & \\
\hline 16）黑斑荫眼蝶 Neope pulahoides（Moore） & 2 & + & & \\
\hline 17) 蒙链荫眼蝶 Neope muirheadii (C.\& R.Felder) & 261 & + & & \\
\hline 18）黄荫眼蝶 Neope contrasta Mell \# & 21 & + & & \\
\hline 19）蓝斑丽眼蝶 Mandarinia regalis (Leech) \# & 2 & + & & \\
\hline 20) 小眉眼蝶 Mycalesis mineus (Linnaeus) \# & 30 & + & & \\
\hline 21) 平顶眉眼蝶 Mycalesis mucianus Fruhstorfer \# & 18 & + & & \\
\hline 22) 稻眉眼蝶 Mycalesis gotama Moore & 4 & & & + \\
\hline 23）拟稻眉眼蝶 Mycalesis francisca (Stoll) & 4 & + & & \\
\hline 24) 白斑眼蝶 Penthema adelma (C.\& R.Felder) \# & 40 & + & & \\
\hline 25) 凤眼蝶 Neorina patria Leech & 1 & + & & \\
\hline 26) 唯眼蝶 Ypthima baldus (Fabricius) \# & 364 & & & + \\
\hline 27）前雾濖眼蝶 Ypthima praenubila Leech \# & 3 & + & & \\
\hline 28) 幽翟眼蝶 Ypthima conjuncta Lecch \# & 5 & + & & \\
\hline 29) 密纹翟眼蝶 Ypthima multistriata Butler \# & 62 & & & + \\
\hline 30) 古眼蝶 Palaeonympha opalina Butler & 2 & + & & \\
\hline 31）朴喙蝶 Libythea lepita Moore & 3 & & & + \\
\hline 32) 虎斑蝶 Danaus genutia (Cramer) \# & 7 & + & & \\
\hline 33）青斑蝶 Tirumala limniace (Cramer) \# & 7 & + & & \\
\hline 34) 绢斑蝶 Parantica agles (Stoll) \# & 4 & + & & \\
\hline 35）拟旖斑蝶 Ideopsis similis (Linnaeus)＃ & 5 & + & & \\
\hline 36) 幻紫斑蝶 Euploea core (Cramer) \# & 1 & + & & \\
\hline 37) 纹环蝶 Aemona amathusia (Hewitson) & 6 & + & & \\
\hline 38）箭环蝶 Stichophthalma howqua (Westwood) & 168 & + & & \\
\hline 39) 华西箭环蝶 Stichophthalma suffuse Leech \# & 1 & + & & \\
\hline 40) 灰翅串珠环蝶 Faunis aerope (Leech) \# & 4 & + & & \\
\hline 41) 亖麻珍蝶 Acraea violae (Fabricius)＃ & 178 & + & & \\
\hline 42) 白带锯蛱蝶 Cethosia biblis (Drury) \# & 1 & + & & \\
\hline 43）黄襟蛱蝶 Cupha erymanthis (Drury)＃ & 2 & + & & \\
\hline 44）绿豹蛱蝶 Argynnis paphia (Linnaeus) & 3 & & & + \\
\hline 45）斐豹蛱蝶 Argyreus hyperbius (Linnaeus) & 156 & & & + \\
\hline 46）老豹蛱蝶 Argyronome laodice Pallas \# & 15 & & & + \\
\hline 47）青豹蛱蝶 Damora sagana Doubledag & 47 & & & + \\
\hline 48) 银豹蛱蝶 Childrena children (Gray) & 71 & + & & \\
\hline 49) 枯叶蛱蝶 Kallima inachus (Doyère) \# & 8 & + & & \\
\hline
\end{tabular}


洪芳, 向颖, 陈朝阳, 孙亮先, 罗春首, 蒋国芳 (2020) 龙栖山自然保护区蝴蝶群落多样性及区系. 生物多样性, 28 (8): 1003-1007. http://www.biodiversity-science.net/CN/10.17520/biods.2020203

\begin{tabular}{|c|c|c|c|c|}
\hline 种名及分类归属 & 个体数 & 东洋种 & 古北种 & 广布种 \\
\hline Species and classification & $\begin{array}{l}\text { Individual } \\
\text { number }\end{array}$ & $\begin{array}{l}\text { Oriental } \\
\text { species }\end{array}$ & $\begin{array}{l}\text { Palaearctic } \\
\text { species }\end{array}$ & $\begin{array}{l}\text { Widespread } \\
\text { species }\end{array}$ \\
\hline 50）琉璃蛱蝶 Kaniska canace (Linnaeus) & 16 & + & & \\
\hline 51）黄钩蛱蝶 Polygonia c-aureum (Linnaeus) & 12 & & & + \\
\hline 52) 大红蛱蝶 Vanessa indica (Herbst) & 2 & & & + \\
\hline 53）小红蛱蝶 Vanessa cardui (Linnaeus) & 12 & & & + \\
\hline 54）美眼蛱蝶 Junonia almanac (Linnaeus) & 44 & + & & \\
\hline 55）钩翅眼蛱蝶 Junonia iphita (Cramer) \# & 6 & + & & \\
\hline 56) 散纹盛蛱蝶 Symbrenthia lilaea Hewitson \# & 5 & + & & \\
\hline 57）花豹盛蛱蝶 Symbrenthia hypselis (Godart) \# & 5 & + & & \\
\hline 58) 凤尾蛱蝶 Polyura arja (C.\& R.Felder) \# & 5 & + & & \\
\hline 59) 二尾蛱蝶 Polyura narcaea (Hewitson) & 4 & & & + \\
\hline 60) 忘忧尾蛱蝶 Polyura nepenthes (Grose-Smith) \# & 5 & + & & \\
\hline 61) 白带螯蛱蝶 Charaxes bernardus (Fabricius) & 5 & + & & \\
\hline 62) 迷蛱蝶 Mimathyma chevana (Moore) \# & 1 & + & & \\
\hline 63) 罗蛱蝶 Rohana parisatis (Westwood) \# & 18 & + & & \\
\hline 64）傲白蛱蝶 Helcyra superba Leech \# & 13 & + & & \\
\hline 65）黄帅蛱蝶 Sephisa princeps (Fixsen) \# & 4 & & & + \\
\hline 66）黑脉蛱蝶 Hestina assimilis (Linnaeus) & 4 & & & + \\
\hline 67）白裳猫蛱蝶 Timelaea albescens（Oberthür） & 15 & + & & \\
\hline 68）素饰蛱蝶 Stibochiona nicea (Gray) & 4 & + & & \\
\hline 69) 电蛱蝶 Dichorragia nesimachus (Doyère) \# & 3 & + & & \\
\hline 70)网丝蛱蝶 Cyrestis thyodamas Boisduval & 8 & + & & \\
\hline 71) 红裙边翠蛱蝶 Euthalia irrubescens Grose-Smith \# & 9 & + & & \\
\hline 72) 尖翅翠蛱蝶 Euthalia phemius (Doubledag) \# & 3 & + & & \\
\hline 73）嘉翠蛱蝶 Euthalia kardama (Moore) \# & 1 & + & & \\
\hline 74）黄翅翠蛱蝶 Euthalia kosempona Fruhstorfer \# & 40 & + & & \\
\hline 75）黄铜翠蛱蝶 Euthalia nara (Moore)＃ & 2 & + & & \\
\hline 76) 华东翠蛱蝶 Euthalia rickettsi Hall \# & 6 & + & & \\
\hline 77) 明带翠蛱蝶 Euthalia yasuyukii Yoshino \# & 3 & + & & \\
\hline 78）褐裙玳蛱蝶 Tanaecia jahnu (Moore) \# & 2 & + & & \\
\hline 79）邚蛱蝶 Abrota ganga Moore \# & 5 & + & & \\
\hline 80) 奥蛱蝶 Auzakia danava (Moore) \# & 3 & + & & \\
\hline 81）断眉线蛱蝶 Limenitis doerriesi Staudinger \# & 1 & & & + \\
\hline 82) 残锷线蛱蝶 Limenitis sulpitia (Cramer) \# & 70 & + & & \\
\hline 83）双色带蛱蝶 Athyma cama Moore \# & 4 & + & & \\
\hline 84）玄珠带蛱蝶 Athyma perius (Linnaeus) \# & 2 & + & & \\
\hline 85) 新月带蛱蝶 Athyma selenophora (Kollar) \# & 7 & + & & \\
\hline 86）孤斑带蛱蝶 Athyma zeroca Moore \# & 2 & + & & \\
\hline 87）相思带蛱蝶 Athyma nefte (Cramer) \# & 3 & + & & \\
\hline 88）玉杵带蛱蝶 Athyma jina Moore \# & 38 & + & & \\
\hline 89）缕蛱蝶 Litinga cottini（Oberthür）\# & 3 & + & & \\
\hline 90) Y纹俳蛱蝶 Parasarpa dudu (Doubledag) \# & 2 & + & & \\
\hline
\end{tabular}


洪芳, 向颖, 陈朝阳, 孙亮先, 罗春首, 蒋国芳 (2020) 龙栖山自然保护区蝴蝶群落多样性及区系. 生物多样性, 28 (8): 1003-1007. http://www.biodiversity-science.net/CN/10.17520/biods.2020203

\begin{tabular}{|c|c|c|c|c|}
\hline 种名及分类归属 & 个体数 & 东洋种 & 古北种 & 广布种 \\
\hline Species and classification & $\begin{array}{l}\text { Individual } \\
\text { number }\end{array}$ & $\begin{array}{l}\text { Oriental } \\
\text { species }\end{array}$ & $\begin{array}{l}\text { Palaearctic } \\
\text { species }\end{array}$ & $\begin{array}{l}\text { Widespread } \\
\text { species }\end{array}$ \\
\hline 91) 小环蛱蝶 Neptis sappho (Pallas) & 18 & & & + \\
\hline 92) 中环蛱蝶 Neptis hylas (Linnaeus) & 28 & + & & \\
\hline 93) 耶环蛱蝶 Neptis yerburii Butler \# & 3 & + & & \\
\hline 94) 珂环蛱蝶 Neptis clinia Moore \# & 72 & + & & \\
\hline 95）娑环蛱蝶 Neptis soma Moore & 5 & + & & \\
\hline 96) 娜环蛱蝶 Neptis nata Moore \# & 2 & + & & \\
\hline 97）宽环蛱蝶 Neptis mahendra Moore \# & 2 & + & & \\
\hline 98）弥环蛱蝶 Neptis miah Moore & 9 & + & & \\
\hline 99) 断环蛱蝶 Neptis sankara Kollar & 2 & + & & \\
\hline 100）卡环蛱蝶 Neptis cartica Moore＃ & 1 & + & & \\
\hline 101）司环蛱蝶 Neptis speyeri Staudinger \# & 3 & & & + \\
\hline 102）啡环蛱蝶 Neptis philyra Ménétriès \# & 2 & & & + \\
\hline 103）阿环蛱蝶 Neptis ananta Moore & 4 & + & & \\
\hline 104）莲花环蛱蝶 Neptis hesione Leech & 2 & + & & \\
\hline 105）链环蛱蝶 Neptis pryeri Butler \# & 2 & & & + \\
\hline 106）金蟠蛱蝶 Pantoporia hordonia (Stoll) \# & 1 & + & & \\
\hline \multicolumn{5}{|l|}{4 灰蝶科 Lycaenidae } \\
\hline 1) 白带褐蚬蝶 Abisara fylloides (Westwood) \# & 4 & + & & \\
\hline 2) 长尾褐蚬蝶 Abisara neophron (Hewitson) & 3 & + & & \\
\hline 3) 白蚬蝶 Stiboges nymphidia Butler \# & 7 & + & & \\
\hline 4) 波蚬蝶 Zemeros flegyas (Cramer) & 13 & + & & \\
\hline 5) 德锉灰蝶 Allotinus drumila (Moore) \# & 4 & + & & \\
\hline 6) 中华云灰蝶 Miletus chinensis C.Felder \# & 71 & + & & \\
\hline 7) 蚜灰蝶 Taraka hamada Druce & 95 & & & + \\
\hline 8) 尖翅银灰蝶 Curetis acuta Moore & 49 & + & & \\
\hline 9) 线灰蝶 Thecla betula (Linnaeus) \# & 3 & & & + \\
\hline 10) 青灰蝶 Antigius attilia (Bremer) \# & 4 & & & + \\
\hline 11）虎斑灰蝶 Yamamotozephyrus kwangtungensis（Forster）\# & 4 & + & & \\
\hline 12) 百娆灰蝶 Arhopala bazalus (Hewitson) \# & 1 & + & & \\
\hline 13) 齿翅娆灰蝶 Arhopala rama (Kollar) \# & 12 & + & & \\
\hline 14) 小娆灰蝶 Arhopala paramuta (deNicéville) \# & 4 & + & & \\
\hline 15）银线灰蝶 Spindasis lohita (Horsfield) \# & 3 & + & & \\
\hline 16) 生灰蝶 Sinthusa chandrana (Moore) \# & 8 & + & & \\
\hline 17) 古楼娜灰蝶 Nacaduba kurava (Moore) \# & 16 & + & & \\
\hline 18）雅灰蝶 Jamides bochus (Stoll) \# & 3 & + & & \\
\hline 19）酢酱灰蝶 Zizeeria maha (Kollar) \# & 234 & & & + \\
\hline 20) 吉灰蝶 Zizeeria karsandra (Moore) \# & 3 & + & & \\
\hline 21）毛眼灰蝶 Zizina otis (Fabricius) \# & 33 & + & & \\
\hline 22) 长腹灰蝶 Zizula hylax (Fabricius) \# & 4 & + & & \\
\hline 23) 蓝灰蝶 Everes argiades (Pallas) \# & 36 & & & + \\
\hline 24) 点玄灰蝶 Tongeia filicaudis (Pryer) \# & 3 & & & + \\
\hline
\end{tabular}


洪芳, 向颖, 陈朝阳, 孙亮先, 罗春首, 蒋国芳 (2020) 龙栖山自然保护区蝴蝶群落多样性及区系. 生物多样性, 28 (8): 1003-1007. http://www.biodiversity-science.net/CN/10.17520/biods.2020203

\begin{tabular}{|c|c|c|c|c|}
\hline $\begin{array}{l}\text { 种名及分类归属 } \\
\text { Species and classification }\end{array}$ & $\begin{array}{l}\text { 个体数 } \\
\text { Individual } \\
\text { number }\end{array}$ & $\begin{array}{l}\text { 东洋种 } \\
\text { Oriental } \\
\text { species }\end{array}$ & $\begin{array}{l}\text { 古北种 } \\
\text { Palaearctic } \\
\text { species }\end{array}$ & $\begin{array}{l}\text { 广布种 } \\
\text { Widespread } \\
\text { species }\end{array}$ \\
\hline 25) 玄灰蝶 Tongeia fischeri ((Eversmann) \# & 4 & & & + \\
\hline 26）黑丸灰蝶 Pithecops corvus Fruhstorfer \# & 1 & + & & \\
\hline 27) 琉璃灰蝶 Celastrina argiola (Linnaeus) \# & 3 & & & + \\
\hline 28) 一点灰蝶 Neopithecops zalmora (Butler) \# & 2 & + & & \\
\hline 29) 紫灰蝶 Chilades lajus (Stoll) \# & 21 & + & & \\
\hline 30) 曲纹紫灰蝶 Chilades pandava (Horsfield) \# & 15 & + & & \\
\hline \multicolumn{5}{|l|}{5 弄蝶科 Hesperiidae } \\
\hline 1) 绿弄蝶 Choaspes benjaminii (Guérin—Méneville) & 8 & + & & \\
\hline 2) 半黄绿弄蝶 Choaspes hemixanthus Rothschild \& Jordan \# & 1 & + & & \\
\hline 3) 斑星弄蝶 Celaenorrhinus maculosus C.\& R.Felder & 4 & + & & \\
\hline 4) 四川星弄蝶 Celaenorrhinus patula deNicéville \# & 1 & + & & \\
\hline 5) 黄襟弄蝶 Pseudocoladenia dan (Fabricius) \# & 4 & + & & \\
\hline 6) 黑弄蝶 Daimio tethys (Ménétriés) & 2 & & & + \\
\hline 7) 滚边裙弄蝶 Tagiades cohaerens Mabille \# & 3 & + & & \\
\hline 8) 白弄蝶 Abraximorpha davidii (Mabille) \# & 2 & + & & \\
\hline 9) 小弄蝶 Leptalina unicolor (Bremer \& Grey) \# & 3 & & + & \\
\hline 10) 黄斑弄蝶 Ampittia dioscorides (Fabricius) \# & 6 & + & & \\
\hline 11) 钩形黄斑弄蝶 Ampittia virgate (Lecch) \# & 2 & + & & \\
\hline 12) 旖弄蝶 Isoteinon lamprospilus C.\& R.Felder \# & 2 & + & & \\
\hline 13) 腌翅弄蝶 Astictopterus jama C.\& R.Felder \# & 2 & + & & \\
\hline 14) 曲纹袖弄蝶 Notocrypta curvifascia (C.\& R.Felder) \# & 2 & + & & \\
\hline 15) 姜弄蝶 Udaspes folus (Gramer) & 1 & + & & \\
\hline 16) 素弄蝶 Suastus gremius (Fabricius) \# & 1 & + & & \\
\hline 17）黄弄蝶 Taractrocera flavoides Leech \# & 5 & + & & \\
\hline 18) 孔子黄室弄蝶 Potanthus confucius (C.\& R.Felder) & 4 & + & & \\
\hline 19) 曲纹黄室弄蝶 Potanthus flavus (Murray) & 3 & & & + \\
\hline 20) 宽纹黄室弄蝶 Potanthus pava (Fruhstorfer) \# & 4 & + & & \\
\hline 21）严氏黄室弄蝶 Potanthus yani Huang \# & 2 & + & & \\
\hline 22) 黄纹长标弄蝶 Telicota ohara (Plötz) \# & 4 & + & & \\
\hline 23) 黑脉长标弄蝶 Telicota besta Evans \# & 1 & + & & \\
\hline 24) 直纹稻弄蝶 Parnara guttata (Bremer \& Grey) & 18 & & & + \\
\hline 25) 曲纹稻弄蝶 Parnara ganga Evans \# & 4 & + & & \\
\hline 26) 刺纹孔弄蝶 Polytremis zina (Evans) & 3 & & & + \\
\hline 27) 黑标孔弄蝶 Polytremis mencia (Moore) \# & 3 & + & & \\
\hline 28) 盒纹孔弄蝶 Polytremis theca (Evans) \# & 3 & + & & \\
\hline 29) 中华谷弄蝶 Pelopidas sinensis (Mabille) \# & 2 & & & + \\
\hline 合计 Total & 5171 & 151 & 1 & 41 \\
\hline
\end{tabular}




\section{附录 2 蝴蝶在各样线的分布信息}

Appendix 2 Distribution information of butterflies in each sample line

\begin{tabular}{|c|c|c|c|c|c|}
\hline 样线 Lines & 编码 Code & 海拔 (m) Altitude & 起点 Starting point & 终点 Endpoint & 种类 Species \\
\hline 龙潭 & 3500961001 & $533-622$ & $26.5423^{\circ} \mathrm{N}$ & $26.5558^{\circ} \mathrm{N}$ & 灰线瘪风蝶、 \\
\hline
\end{tabular}

Longtan $\quad 117.3221^{\circ} \mathrm{E} \quad 117.3225^{\circ} \mathrm{E}$

白带黛眼蝶、曲纹黛眼蝶、深山黛眼蝶、连纹黛眼蝶、黄荫眼蝶、嗖眼蝶、前雾唯眼蝶、密纹翟眼蝶、蓝 斑丽眼蝶、虎斑蝶、箭环蝶、绿豹蛱蝶、斐豹蛦蝶、老豹蛱蝶、琉璃蛱蝶、钩翅眼蛱蝶、二尾蛱蝶、傲白 蛱蝶、华东翠蛱蝶、残锷线蛱蝶、玉杵带蛱蝶、莲花环蛱蝶、小环蛱蝶、中环蛱蝶、珂环蛱蝶、白蚬蝶、 波蚬蝶、中华云灰蝶、蚜灰蝶、尖翅银灰蝶、虎斑灰蝶、百娆灰蝶、齿翅娆灰蝶、酢浆灰蝶、玄灰蝶、斑 星弄蝶、四川星弄蝶、黄襟弄蝶、滚边裙弄蝶、曲纹袖弄蝶、严氏皇室弄蝶、黄纹长标弄蝶

$\begin{array}{lllll}\text { 沙溪仔 } & 3500961003 & 693-794 & 26.5250^{\circ} \mathrm{N} & 26.5298^{\circ} \mathrm{N} \\ \text { Shaxi-zhai } & & & 117.2995^{\circ} \mathrm{E} & 117.2959^{\circ} \mathrm{E}\end{array}$

灰线槥风蝶、玉斑风蝶、蓝风蝶、青风蝶、宽边黄粉蝶、檗黄粉蝶、菜粉蝶、东方菜粉蝶、暮眼蝶、黛眼

Shaxi-zhai

$117.2995^{\circ} \mathrm{E}$

$117.2959^{\circ} \mathrm{E}$

$\begin{array}{lllll}\text { 小王-水库 } & 3500961005 & 290-279 & 26.4913^{\circ} \mathrm{N} & 26.4944^{\circ} \mathrm{N} \\ \text { 段 } & & & 117.3409^{\circ} \mathrm{E} & 117.3390^{\circ} \mathrm{E} \\ \text { Xiaowang } & & & \\ \text { reservoir } & & & & \\ \text { 沙洲村 } & 3500961006 & 289-358 & 26.2914^{\circ} \mathrm{N} & 26.2952^{\circ} \mathrm{N} \\ \text { Shazhou- } & & & 117.1997^{\circ} \mathrm{E} & 117.1826^{\circ} \mathrm{E}\end{array}$

chun

\begin{tabular}{lllll} 
田角 & 3500961002 & $816-839$ & $26.5027^{\circ} \mathrm{N}$ & $26.5170^{\circ} \mathrm{N}$ \\
Tianjiao & & & $117.2448^{\circ} \mathrm{E}$ & $117.2682^{\circ} \mathrm{E}$ \\
\hline
\end{tabular}

蝶、连纹黛眼蝶、曲纹黛眼蝶、黑斑荫眼蝶、蒙链荫眼蝶、黄荫眼蝶、小眉眼蝶、幽翟眼蝶、密纹藿眼蝶、 虎斑蝶、绢斑蝶、纹环蝶、箭环蝶、华西箭环蝶、芦麻珍蝶、斐豹蛦蝶、琉璃蛱蝶、黄钩蛱蝶、华东翠蛱 蝶、网丝蛱蝶、残锷线蛱蝶、新月带蛱蝶、孤斑带蛱蝶、小环蛱蝶、珂环蛱蝶、弥环蛱蝶、司环蛱蝶、链 环蛱蝶、波蚬蝶、蚜灰蝶、虎斑灰蝶、齿翅娆灰蝶、小娆灰蝶、酷酱灰蝶、蓝灰蝶、一点灰蝶、黄弄蝶、 直纹稻弄蝶

宽尾风蝶、玉玟风蝶、美风蝶、宽边黄粉蝶、东方菜粉蝶、黛眼蝶、白带黛眼蝶、蛇神黛眼蝶、曲纹黛眼 蝶、小眉眼蝶、唯眼蝶、密纹唯眼蝶、虎斑蝶、残锷线蛱蝶、箭环蝶、钩翅眼蛱蝶、黄铜翠蛱蝶、佪蛱蝶、 新月带蛱蝶、玉杵带蛱蝶、中环蛱蝶、白蚬蝶、波蚬蝶、中华云灰蝶、蚜灰蝶、百娆灰蝶、齿翅娆灰蝶、 小娆灰蝶、酢酱灰蝶、蓝灰蝶、点玄灰蝶、斑星弄蝶、旖弄蝶、黄纹长标弄蝶

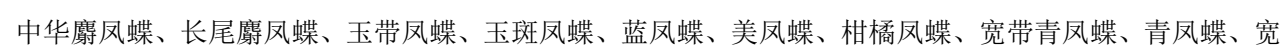
边黄粉蝶、东方菜粉蝶、连纹黛眼蝶、蒙链荫眼蝶、白斑眼蝶、小眉眼蝶、平顶眉眼蝶、翄眼蝶、青斑蝶、 箭环蝶、芝麻珍蝶、斐豹蛱蝶、青豹蛱蝶、银豹蛱蝶、琉璃蛱蝶、美眼蛱蝶、忘忧尾蛱蝶、傲白蛱蝶、黄 帅蛱蝶、红裙边翠蛱蝶、黄翅翠蛱蝶、残锷线蛱蝶、新月带蛱蝶、Y纹俳蛱蝶、珂环蛱蝶、波蚬蝶、蚜灰 蝶、尖翅银灰蝶、小娆灰蝶、古楼娜灰蝶、酢浆灰蝶、吉灰蝶、黄斑弄蝶、直纹稻弄蝶

长尾鹰风蝶、宽带青风蝶、青风蝶、宽边黄粉蝶、东方菜粉蝶、连纹黛眼蝶、白带黛眼蝶、曲纹黛眼蝶、 阿芒荫眼蝶、蒙链荫眼蝶、黄荫眼蝶、小眉眼蝶、白斑眼蝶、謴眼蝶、幽唯眼蝶、青斑蝶、斐豹蛱蝶、老 
小沛

350096004

Xiaopei $26.4961^{\circ} \mathrm{N}$

$117.2875^{\circ} \mathrm{E}$
豹蛱蝶、银豹蛱蝶、琉璃蛱蝶、黄钩蛱蝶、小红蛱蝶、美眼蛱蝶、罗蛱蝶、傲白蛱蝶、黄帅蛱蝶、白裳猫 蛱蝶、红裙边翠蛱蝶、残锷线蛱蝶、新月带蛱蝶、玉杵带蛦蝶、珂环蛱蝶、中华云灰蝶、蚜灰蝶、尖翅银 灰蝶、银线灰蝶、古楼娜灰蝶、酢浆灰蝶、紫灰蝶、黑弄蝶、黄斑弄蝶、钩形黄斑弄蝶、腌翅弄蝶、直纹 稻弄蝶、曲纹稻弄蝶

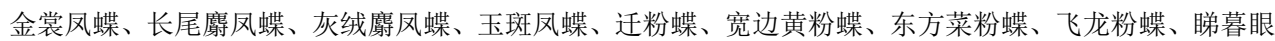
蝶、连纹黛眼蝶、白带黛眼蝶、曲纹黛眼蝶、阿芒荫眼蝶、布莱荫眼蝶、蒙链荫眼蝶、黄荫眼蝶、小眉眼 蝶、平顶眉眼蝶、白斑眼蝶、唯眼蝶、朴鲒蝶、青斑蝶、纹环蝶、箭环蝶、斐豹蛱蝶、青豹蛱蝶、银豹蛱 蝶、琉璃蛱蝶、黄钩蛱蝶、小红蛱蝶、美眼蛱蝶、散纹盛蛱蝶、二尾蛱蝶、白带螯蛱蝶、罗蛱蝶、傲白蛱 蝶、白裳猫蛱蝶、网丝蛱蝶、黄翅翠蛦蝶、邚蛱蝶、残锷线蛦蝶、新月带蛱蝶、玉杵带蛱蝶、中环蛱蝶、 珂环蛱蝶、弥环蛱蝶、中华云灰蝶、蚜灰蝶、尖翅银灰蝶、虎斑灰蝶、齿翅娆灰蝶、银线灰蝶、古楼娜灰 蝶、酷浆灰蝶、毛眼灰蝶、斑星弄蝶、白弄蝶、腌翅弄蝶、曲纹稻弄蝶 